\title{
A Time Motion and Analysis of Partnering Skills in Latin-American Dance Using a Semi-Automatic Tracking System: A Case Study
}

\author{
Petra Zaletel ${ }^{1}$ \\ 'University of Ljubljana, Faculty of Sport, Ljubljana, Slovenia
}

\begin{abstract}
The aim of the research was analysing motion and partnering skills by examining different relation positions between dance partners, distance covered and speed of movement in Latin-American dance. The sample consisted of three elite Latin-American dance couples simultaneously danced each of five Latin dances consecutively. Dances were recorded using two cameras - first was used to determine the path of the dancers' movement (secured to the ceiling of the hall), the second camera was located on the side of the dance floor to facilitate annotation of the dancers' posture relationships. The overhead footage was later transferred to a PC and analysed with the tracking system. With a specifically designed annotation system we categorised five different relationship postures exhibited between male and female dancers. We used two-way ANOVA for establishing differences in motion regarding gender and different dances. Results showed no differences between gender, but significant differences in speed and distance covered between dances. Samba and Passodoble seemed to be the most dynamic dances, with longest distance covered and highest speed of movement, followed by Cha Cha and Jive whereas activity in the Rumba took place in a relatively small area of the dance floor. Dancers were in open positions $99 \%$ of the time (except Passodoble $-87 \%$ and Cha Cha $-91 \%$ ), either touching or not touching each other, with focus on the partner evident between $40 \%$ and $60 \%$ of the time in all dances. These findings tended to confirm rather than dispute the apriori expectations of individual dance choreographies.
\end{abstract}

Keywords: Sport Dance, Choreography, Positional Relationships, Motion Analysis

\section{Introduction}

Sport dance consists of five standard (Slow waltz, Viennese waltz, Tango, Foxtrot and Quickstep) and five Latin American dances (Samba, Cha Cha, Rumba, Passodoble and Jive) with couples competing in a combination of all ten dances or in each group (standard or Latin American) separately. These dances are complex and require fine motor skills to exhibit "virtuosic control of body movement in a specific rhythm and space" (Da Silva \& Bonorino, 2008). Dance is a sequence of "gestures, steps and movements with musical rhythm that express affectionate states" and also expresses "emotions through physical move- ment" (Dantas, 1999). Laban (1963) considered dance as a communication tool and tried to extract parameters which could be related to the dance's expressive power.

The duration of each Latin American dance varies from 90 to $120 \mathrm{sec}$ consisting of numerous movement structures involving different steps, turns, rapid changes of movement direction and elements of balance, which all require strength and flexibility (Lukić, Bijelić, Zagorc, \& Šebić, 2011). Dancesport is in the very heavy to extremely heavy category in energy expenditure (mean heart rate: male 175.2 \pm 10.7 , female $178.6 \pm 8.6 \mathrm{bpm}$ ) and utilizes both aerobic and anaerobic energy systems (McCabe,

Correspondence:

Montenegro Petra Zaletel,

Sport University of Ljubljana, Faculty of Sport, Gortanova 22, 1000 Ljubljana, Slovenia e-mail: petra.zaletel@fsp.uni-lj.si 
Wyon, Ambegaonkar, \& Reeding, 2013). During training heart rates as high as $178 \mathrm{bpm}$ in Cha Cha, $182 \mathrm{bpm}$ in Passodoble and $187 \mathrm{bpm}$ in Jive have been recorded indicating that Latin-American dance is a high intensity activity with anaerobic metabolic demands (Zagorc, Karpljuk, \& Friedl, 1999). Additionally, Wyon, Abt, Reeding, Head, \& Sharp (2004) found similar results in 16-19 years old dancers. An increased demand placed on the fast glycolytic and aerobic systems has been reported during stage performance and dance training sessions - classes (Wyon et al., 2004).

Previous research in dance motion, using semiautomatic tracking system (Zaletel, Vučković, Rebula, \& Zagorc, 2010a), showed that the paths of male and female standard dancers were almost identical as opposed to Latin-American dance. A subsequent study that compared high level adult and youth standard dancers showed that the dynamics of movement (distance covered and speed) were greater in the adult couples ( $\mathrm{Za}$ letel, Vučković, James, Rebula, \& Zagorc, 2010b). The authors suggested that the younger dancers were using a basic choreography travelling in circles while the adult couples used more complex choreographies, consistently utilising the inner space of the dance floor (Prosen, James, Dimitriou, Perš, \& Vučković, 2013).

Time and space are two essential components that contribute to the dancer's expressiveness (Minvielle-Moncla, Audeffren, Macar, \& Vallet, 2008). Precision, accuracy and synchrony in movement execution with the implementation and mastering of fine motor skills and dance figures determine fluidity and successful choreography (Vermey, 1994). The dancers/choreographers try to express their feelings and emotions through an "aesthetic expressive movement form" (Vermey, 1994). Although human movement can convey emotional information (Camurri \& Ferrentino, 1999), it is impossible to examine these emotional components with large scale motion measurements (Vučković, Perš, James, \& Hughes, 2009).

Overall dance performance is judged based on the dancer's technical skills and aesthetic performance (World Dance Sport Federation, 2019). Artistic component includes partnering skills, choreography and presentation. One of the critical parts of the partnering skills are different positions that dance partners adopt.

In Latin-American dance the standard position (as commonly used in standard dances) is referred to as the "closed" position where the female left hand is on the male's right shoulder, her right hand is in his left hand and his right hand is placed on the upper part of her back. Unlike standard dance this position is not as commonly used and dancers adopt other positions which are referred to as the "open" position. Within this open position the male and female dancer can either touch or not touch each other. Dance partners can be often apart and facing away from each other which results in difficulty for synchronization and coordination of their overall dance performance. As they dance together, female and male dancer are in certain relation with their bodies to each other.

Previous research has suggested that in standard dance the speed and distance covered by dancers is most likely to be due to the choreography (Zaletel et al., 2010b) and also due to different level of performance - better couples are faster and travel further distance (Prosen, 2013), but this remains to be determined through motion analysis in Latin-American dance. To authors knowledge partnering skills in Latin-American dance was not often investigated in sports science. Consequently, a reductionist approach was used in this study which focused on analysing partnering skills by examining different positions between dance partners, distance covered and speed of movement.

\section{Methods}

\section{Participants}

Three elite internationally ranked Latin-American dance couples volunteered to participate in this study. In average three male dancers were $23.8( \pm 2.2)$ years old, $181.3 \mathrm{~cm}( \pm 2.2)$ high and they weighted $70.2 \mathrm{~kg}( \pm 1.6)$. Their female partners were 21.5 years old $( \pm 3.6), 165.7 \mathrm{~m}( \pm 6.6)$ high and they weighted in average $55.3 \mathrm{~kg}( \pm 5.9)$. Their average time of training per week was $22.5 \mathrm{~h}( \pm 4.5)$. All dance couples had reached the finals of WDSF International Open competitions in 2017. The study was approved from the authors' University Ethics committee.

\section{Procedures}

All couples simultaneously danced each of five LA dances consecutively, with each dance lasting 90 seconds and a pause of 30 seconds between each dance, as is usual for competitions (World Dance Sport Federation, 2019). Dances were recorded directly to DVD using two cameras (Ultrak KC CCD Color CP 7501 , Japan) recording at a frequency of 25 frames per second. The first camera was used to determine the path of the dancers' movement and was secured to the ceiling of the hall which enabled the recording of a rectangular projection on the dance area (20x20m). By using a wide-angle lens (Ultrak KL2814IS, Japan) the entire dance area was in view. A second camera was located on the side of the dance floor to facilitate annotation of the details of the dancers' posture relationships.

The footage was transferred to a PC post event and analysed with a semi-automated tracking system, which is a large scale human tracking motion measurement system based on computer vision technology (Perš, Bon, Kovačič, Šibila, \& Dežman, 2002). The system proved to be suitable for analysing dancers' motion in LA and BR dance (Prosen et al., 2013).

\section{Sample of variables}

Preston-Dunlop (1981) listed the basic structures of positions in partnering skills, in development from first to the last: (1) aware of, focus, addressing, (2) near to, proximity, close but not touching, (3) touching, (4) supporting, taking some weight, (5) surrendering, without touch, (6) surrendering with touch, linking, embracing and (7) carrying, holding, lifting. Because of difficulties in following some elements in dance performance (turns are made within part of a second - which means small part of a second dance partners are in open position without focus and touching each other, another short moment at the end of turn they're already in closed position) we made it more simple and clear. So, we adapted the above structure by joining some of them into 5 positions: (1) open position relationship touching each other and focus on partner, (2) open position relationship touching each other without focus, (3) closed position relationship, (4) open position without touching with focus on partner and (5) open position without touching and without focus.

\section{Data analysis}

Descriptive statistics was used for analysing distance covered and speed of movement within each LA dance. Two-way ANOVA was used to establish differences in speed and distance covered between different gender (male and female dancers) and between different Latin-American dance. Descriptive statistics was also used for analysing different proportions of each relationship position between female and male dancer in each LA dance.

\section{Results}

A two-way ANOVA (dance and with repeated measures for gender) found no significant interaction or main effect for differences in average speed between genders (Table 1). However 
significant differences between dances were found (Table 3). Results revealed that the Rumba had the lowest average speed,
Cha Cha and Jive were much faster but still slower than Samba and Passadouble.

Table 1. Average speeds (m. s-1) in all 5 LA dances and differences in speed between gender

\begin{tabular}{cccccccccccc}
\hline & \multicolumn{2}{c}{ 1st couple } & \multicolumn{2}{c}{ 2nd couple } & \multicolumn{2}{c}{ 3rd couple } & \multicolumn{2}{c}{ Average speed } \\
\hline & Male & Female & Male & Female & Male & Female & $\begin{array}{c}\text { All males } \\
\text { Mean (SD) }\end{array}$ & $\begin{array}{c}\text { All females } \\
\text { Mean (SD) }\end{array}$ & F & $p$ \\
\hline Samba & 0.81 & 0.80 & 0.91 & 0.73 & 0.95 & 0.78 & $0.89(0.51)$ & $0.77(0.13)$ & 6.646 & 0.061 \\
Cha Cha & 0.67 & 0.65 & 0.63 & 0.66 & 0.61 & 0.63 & $0.64(0.02)$ & $0.64(0.02)$ & 0.257 & 0.639 \\
Rumba & 0.53 & 0.66 & 0.54 & 0.44 & 0.57 & 0.51 & $0.55(0.02)$ & $0.54(0.07)$ & 0.023 & 0.887 \\
Passodoble & 0.88 & 0.83 & 0.89 & 0.84 & 0.80 & 0.86 & $0.85(0.03)$ & $0.84(0.03)$ & 0.200 & 0.678 \\
Jive & 0.66 & 0.66 & 0.68 & 0.67 & 0.73 & 0.59 & $0.69(0.03)$ & $0.64(0.05)$ & 2.344 & 0.201 \\
\hline
\end{tabular}

Note: $\mathrm{F}$ - test difference, $\mathrm{p}$ - statistical significance; Mean - average value; SD - standard deviation

A two-way ANOVA (dance and with repeated measures for gender) found no significant interaction or main effect for differences in distance covered between genders (Table 2). Howev- er significant differences between dances were found (Table 3). Rumba had the lowest distance covered, Cha Cha and Jive greater distance but still less distance than Samba and Passadouble.

Table 2. Distance $(\mathrm{m})$ covered in all $5 \mathrm{LA}$ dances and differences in distance between gender

\begin{tabular}{cccccccccccc}
\hline & \multicolumn{2}{c}{ 1st couple } & \multicolumn{2}{c}{ 2nd couple } & \multicolumn{2}{c}{ 3rd couple } & \multicolumn{2}{c}{ Average distance } \\
\hline & Male & Female & Male & Female & Male & Female & All males & All females & Mean (SD) & Mean (SD) & F \\
\hline Samba & 74.18 & 73.70 & 83.59 & 67.40 & 87.74 & 71.90 & $81.84(5.3)$ & $71.0(2.4)$ & 5.991 & 0.071 \\
Cha Cha & 60.06 & 57.42 & 55.99 & 59.07 & 54.24 & 56.05 & $56.76(2.7)$ & $57.51(1.3)$ & 0.151 & 0.718 \\
Rumba & 43.85 & 54.50 & 44.58 & 36.45 & 46.92 & 42.54 & $45.12(1.2)$ & $44.50(6.7)$ & 0.013 & 0.914 \\
Passodoble & 76.31 & 72.30 & 77.30 & 73.42 & 69.24 & 75.14 & $74.28(3.3)$ & $73.62(1.1)$ & 0.062 & 0.816 \\
Jive & 58.57 & 58.42 & 60.09 & 59.32 & 65.27 & 52.53 & $61.31(2.7)$ & $56.76(2.9)$ & 2.398 & 0.196 \\
\hline
\end{tabular}

Table 3. Differences in average speed and distance between different dances

\begin{tabular}{cccccccc}
\hline & $\begin{array}{c}\text { Samba } \\
\text { Mean }\end{array}$ & $\begin{array}{c}\text { Cha Cha } \\
\text { Mean }\end{array}$ & $\begin{array}{c}\text { Rumba } \\
\text { Mean }\end{array}$ & $\begin{array}{c}\text { Passodoble } \\
\text { Mean }\end{array}$ & $\begin{array}{c}\text { Jive } \\
\text { Mean }\end{array}$ & $\mathrm{F}$ & $\mathrm{p}$ \\
\hline Speed & 0.83 & 0.64 & 0.55 & 0.85 & 0.69 & 32.675 & $0.000^{*}$ \\
Distance & 76.42 & 57.14 & 44.81 & 73.95 & 59.04 & 41.183 & $0.000^{*}$ \\
\hline
\end{tabular}

Note: Mean - average value; $F$ - test difference, $p$ - statistical significance, ${ }^{*}$ - statistical significance $(p<0,01)$

The highest mean speed and the greatest distances covered by dancers were in Samba and Passodoble (Tables 1 and 2) as shown by the paths followed by the couples in this study (Figures 1 and 2).

Cha Cha, Jive and Rumba were characterised by relatively stationary dances (Figures 3 - 5) where each dance couple occupied their own space on the dance floor. Dancing couples tended to have very similar mean speeds and paths. However, in Samba male dancers travelled greater distances and at a higher speed,

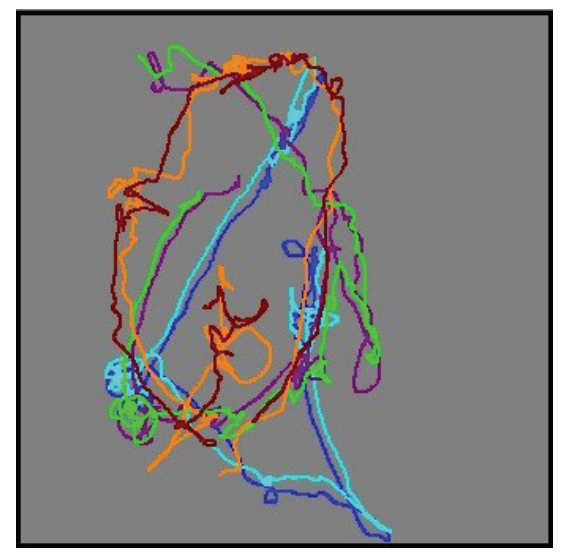

Figure 1. Trajectories of three dance couples in Samba compared to their female partners (Tables 1 and 2).

In comparison to Samba and Passodoble, dancers in Cha Cha, Rumba and Jive tended to dance in their own, relatively small space on the dance floor which was not the classical circle manner (Figures 3 - 5). Dance paths in Cha Cha (Fig. 3) and Jive (Fig. 5) showed slightly more movement in comparison to Rumba (Fig. 4) where there was about $23 \%$ less distance covered in comparison to the other two dances (Table 2).

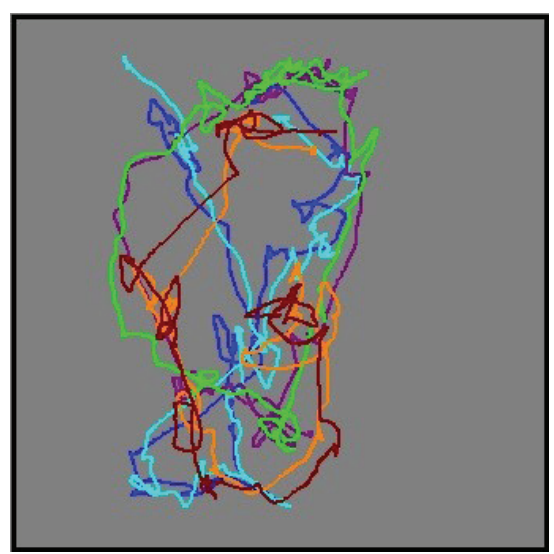

Figure 2. Trajectories of three dance couples in Passodoble 


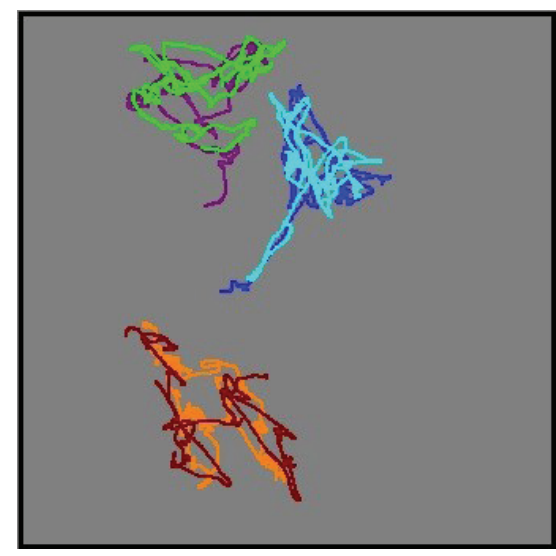

Figure 3. Trajectories of three dance couples in Cha Cha

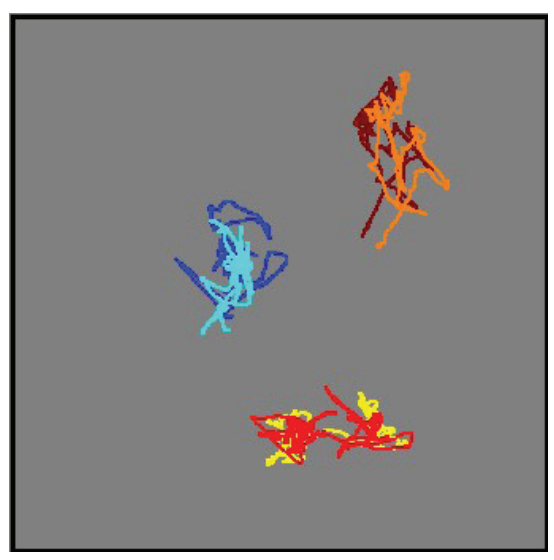

Figure 4. Trajectories of three dance couples in Rumba

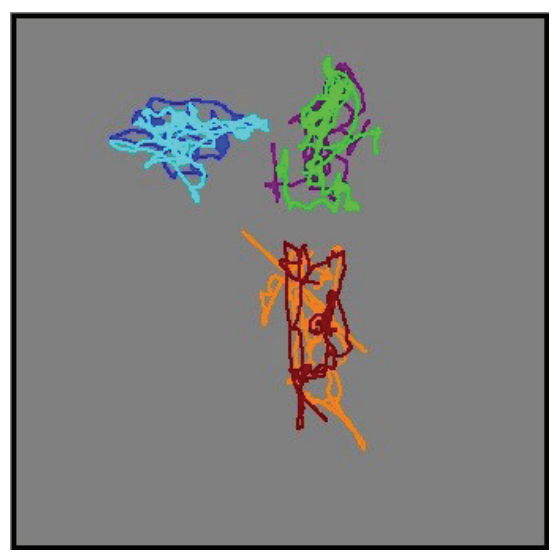

Figure 5. Trajectories of three dance couples in Jive

There were different amounts of time spent at each different relationship posture between dance partners in each dance (Table 4). The closed position was the most similar between dances as it was seldom used in Samba, Rumba and Jive (1\%) although slightly more in Passodoble (13\%) and Cha Cha (9\%). The differences between couples in the same dance, was seen to vary between similar proportions in Jive (e.g. open relationship, no touching and no focus on partner in Jive had a mean proportion of $30.3 \%+2.44 \%$ ) to relatively large differences in Cha Cha (e.g. open relationship, touching and no focus on partner in Cha Cha had an average proportion of $17.93 \%+15.70 \%$ ), showing the occurrence of between couple differences in dance interpretation and choreography.

In Samba dancers spent most of the time $(37,63 \%+7,08 \%)$ in an open relationship, touching each other, without focus on their partner. Also, around $45 \%$ of their time was spent in the open position without touching each other, either focusing on or away from their partner. In Cha Cha $45 \%$ of the time was spent in the open position relationship either holding or not holding each other, while in Rumba (70\%) and Jive (60\%) dancers spent far more time touching each other regardless of the focus in the open relation. Focus on the partner was noticed around $40-60 \%$ in all dances, except the Jive, where $63 \%$ of the focus was away from the partner.

Table 4. Percentage of time spent in each relationship for all five LA dances

\begin{tabular}{|c|c|c|c|c|c|}
\hline $\begin{array}{l}\text { Position relationship, touch, } \\
\text { focus }\end{array}$ & $\begin{array}{c}\text { Samba } \\
\text { Mean } \\
\text { (SD) }\end{array}$ & $\begin{array}{l}\text { Cha Cha } \\
\text { Mean } \\
\text { (SD) }\end{array}$ & $\begin{array}{c}\text { Rumba } \\
\text { Mean } \\
\text { (SD) }\end{array}$ & $\begin{array}{l}\text { Passodoble } \\
\text { Mean } \\
\text { (SD) }\end{array}$ & $\begin{array}{c}\text { Jive } \\
\text { Mean } \\
\text { (SD) }\end{array}$ \\
\hline $\begin{array}{l}\text { 1. Open, touching and focus on } \\
\text { partner }\end{array}$ & $\begin{array}{l}15.23 \\
(3.16)\end{array}$ & $\begin{array}{c}27.43 \\
(12.30)\end{array}$ & $\begin{array}{l}37.37 \\
(8.30)\end{array}$ & $\begin{array}{c}17.70 \\
(10.43)\end{array}$ & $\begin{array}{l}33.53 \\
(5.71)\end{array}$ \\
\hline 2. Open, touching no focus & $\begin{array}{l}37.63 \\
(7.08)\end{array}$ & $\begin{array}{c}17.93 \\
(15.70)\end{array}$ & $\begin{array}{l}29.33 \\
(5.10)\end{array}$ & $\begin{array}{l}18.27 \\
(3.09)\end{array}$ & $\begin{array}{l}24.90 \\
(8.30)\end{array}$ \\
\hline 3. Closed & $\begin{array}{c}1.03 \\
(1.79)\end{array}$ & $\begin{array}{c}9.40 \\
(4.86)\end{array}$ & $\begin{array}{c}1.00 \\
(1.73)\end{array}$ & $\begin{array}{l}13.57 \\
(5.65)\end{array}$ & $\begin{array}{c}0.70 \\
(1.21)\end{array}$ \\
\hline $\begin{array}{l}\text { 4. Open, no touching and focus } \\
\text { on partner }\end{array}$ & $\begin{array}{l}21.50 \\
(5.08)\end{array}$ & $\begin{array}{l}35.27 \\
(20.16)\end{array}$ & $\begin{array}{l}18.67 \\
(2.45)\end{array}$ & $\begin{array}{l}37.87 \\
(5.00)\end{array}$ & $\begin{array}{l}10.63 \\
(9.73)\end{array}$ \\
\hline $\begin{array}{l}\text { 5. Open, no touching and no } \\
\text { focus }\end{array}$ & $\begin{array}{l}24.53 \\
(9.05)\end{array}$ & $\begin{array}{c}9.90 \\
(10.11)\end{array}$ & $\begin{array}{l}13.67 \\
(8.04)\end{array}$ & $\begin{array}{l}12.57 \\
(13.04)\end{array}$ & $\begin{array}{l}30.30 \\
(2.44)\end{array}$ \\
\hline
\end{tabular}

Note: Mean - average value; SD - standard deviation

\section{Discussion}

We analysed some aspects of internationally excellent dance couples' choreographies; motion aspects gave us information about their paths and speed - which was more depending on music rhythm, specific for each LA dance, and relationship aspects between female and male dancer, which seems to define the con- 
tent of each dance. In other words, LA dancers are trying to express, with their movement and choreography, the content of each dance, which seems to be defined by the relationship between the female and male dancer.

The speed of dance movement is an important mechanism for creating the typical expressive movements associated with each LA dance and is determined by the speed of the music (Hoekelmann, 2001). Different tempos and beats help the dancers to create different moods-expressions within the dance choreography. Distances (paths) of each LA dance differed due to different choreographies, which are determined with certain movement structures specific for each dance. In comparison to Samba and Passodoble, paths in Cha Cha, Rumba and Jive took place on smaller space on the dance floor which was not in the shape of classical dance circle. Individual differences were apparent, for example especially in Samba and Jive the distance and speed of male and female dancer differed, but this was probably due to different use of choreography elements; for example when one of the dancers was standing on the spot in Rumba and gesticulating with his/her arms or doing a pose, the other dancer was moving away from or towards her/him, he/she could be spinning around dance partner and their speed and distance was therefore different. That was also the case in Samba, where male dancers had higher speeds and distances then their female partners, probably because males were traveling many times around females, while females were either turning or dancing on the spot. Indeed, this had been found previously (Zaletel et al., 2010b) and is not unusual for some dances as couples often create different paths on the dance floor.

The question remains as to whether these speed and distance measures are significant factors in dance performance.

Samba and Passodoble were the most dynamic dances, with the greatest distance covered and the highest speed of movement. The movement paths in Passodoble reflected the use of a circular direction in space, with sharper changes of movement directions than in Samba where paths were more circled and curved. These results partly agree with the work of Komora (2002) and Štiavnický (2004) who found that fast changes in direction characterised movement patterns during competition LA dances. Paths in Samba also showed relative equality between the partners, confirmed by the similar distances and speeds found for couples. Paths in Samba showed movement in a relatively large circular space, as they would try to exhibit smoothness of movement. These results are in concurrence with the findings of a previous study of physical loads in Latin-American dances (Zaletel et al., 2010a).

The lowest speeds were found in Rumba, probably because dancers were moving around the centre of their own relatively small space rather than the whole of the dance floor. The emphasis for this dance tends to be on body lines and forms using different dynamics in the choreography (Vermey, 1994). The lower speed in the Rumba is thought to facilitate more virtuosic execution (Vermey, 1994). Zaletel et al. (2010a) showed that less experienced dance couples (youth) had higher mean speeds in Rumba than more experienced Adult couples suggesting that speed is related to expertise for this dance. Cha Cha and Rumba have a similar rhythmic structure, where faster Cha Cha has a more playful character, but slower Rumba is a dance with a distinctive character of seduction (Vermey, 1994). Dancing couples tended to have very similar mean speeds and paths in Cha Cha and Rumba which suggests that the choreography is dance specific and maintain some form of relationship between the dance couple. In the Cha Cha emphasis was probably on the legs and feet; on "stepping" which results in the action gestures of the legs and transferring the weight. Dancers had similar speeds in Cha Cha and Jive, which was seen to be an extremely fast and bouncy dance, where the greatest importance was probably gesturing.
Most of the time LA dances were performed in open positions (around 99\% of time in Samba, Rumba and Jive and 87-90\% in Cha Cha and Passodoble). This may suggest, in agreement with Vermey (1994), that dance partners are creating stereotypical non-verbal gender specific behaviour, where the male initiates actions and has less flow in the movement but high energy with sudden, strong, direct moves while the female is more reactive, with more flowing movements and lower energy.

The major position in Samba (open position, touching each other, without focus - 38\%) confirmed that the basic figure in Samba travelled through space, emphasized not the action of travelling, but the zig-zag floor patterns which served to give parading quality of the Samba. Circling in space while travelling or remaining on the spot, was a recurrent spatial structure, which took the focus off the dance partners.

Whilst male LA dancers have been shown to use more focus than females (Vermey, 1994) it was clear in this study that Cha Cha was the dance with most focus between dance partners, dancers were seen to distance themselves before coming close to each other and vice versa throughout the dance. The couples moved in opposite and shared directions as they were non-verbally communicating through their dance. Dancers touched each other most often in the Rumba (67\%) probably to promote the act of seduction. Similarly, $60 \%$ of the time was spent touching each other in Jive, with focus on and off the partner. Less touching of dance partners was obvious in Samba probably due to the many rotation elements of both dancers. The relatively high incidence of the closed position in Passodoble (13\%) seemed to help present a square structure of the dance posture relationship and created a spatial tension between partners and thus gave a stronger appearance.

While dancing the man and woman get in close physical contact, through which a special and intimate relationship is formed between them (Vermey, 1994). Rumba and Cha Cha seemed to have the most focus between the partners either touching or not touching each other, probably because they were creating flirting, seducing moments. Probably focus between dance partners is creating more sincere relationship, which appears to viewer more emotional and has therefore better impact on the audience (and judges). The sincerity of the relationship is probably different between dances due to the characteristics of each dance. In Jive one could say that the dancers were more communicating with audience, perhaps accounting for the fact that for more than half of the time they don't look at each other (55\%). Anyway, all these dramatic movements e.g. hip actions, transferring the weight through the feet, wrapping and rotation actions were not well tracked by SAGIT and therefore not analysed.

Artistic component of dance couple is mostly expressed by their relationship positions in choreography, which helps to create content and character of the dance, expressed through the dancer's presentation (Vermey, 1994).

In order to create the character or qualities so essential to each of the five dances, the dancers in this study displayed very different positional relationships as well as paths of their choreography and speed of movement in each LA dance. It seems sensible, therefore, to suggest that future research annotates the small movements or gestures with hands, head etc., to determine not just frequency of these elements but also the sequence of their occurrence, what would give us even more exact (»deeper«) look into individual LA choreography. It would be interesting to compare structures of choreographies and percentage of postures in each LA dance with the judges' results from a dance competition. This would give us some information about the importance of dance choreography characteristics. Findings of this study could serve as template in process of creating elite dance performance. 
So, future studies still need to annotate the technical elements in more detail to better understand the choreography. With larger samples this may lead to a better understanding of choreography and the determining factors of successful dance performance.

\section{Acknowledgements}

There are no acknowledgements.

\section{Conflict of Interest}

The authors declare that there are no conflicts of interest.

Received: 10 November 2019 | Accepted: 3 December 2019 | Published: 10 January 2020

\section{References}

Camurri, A., \& Ferrentino, P. (1999). Interactive environments for music and multimedia. Multimedia Systems, 7(1), 32-47. doi:10.1007/ s005300050109

Da Silva, A.H., \& Bonorino, K.C. (2008). BMI and flexibility in ballerinas of contemporary dance and classical ballet. Fitness \& Performance Journal, 7(1), 48-51.

Dantas, E.H.M. (1999). Flexibilidade: alongamento e flexionamento. Rio de Janeiro: Shape.

Hoekelmann, A. (2001). Movement formation under the conditions of improvisation and choreography. Acta Kinesiologiae Universitatis Tartuensis, 6, 120-123.

Komora, J. (2002). Technique of Latin-American dances. Bratislava: SZTŠ.

Laban, R. (1963). Modern Educational Dance. Suffolk: The Chaucer Press Ltd.

Lukić A.L., Bijelic, S., Zagorc, M., \& Šebić, L. (2011). The importance of strength in sport dance performance technique. SportLogia, 7(1), 61-67.

McCabe, T.R., Wyon, M., Ambegaonkar, J. P., \& Redding, E. (2013). A bibliographic review of medicine and science research in Dance Sport. Medical problems of performing artists, 28(2), 70-79.

Minvielle-Moncla, J., Audiffren, M., Macar, F., \& Vallet, C. (2008). Overproduction timing errors in expert dancers. Journal of Motor Behaviour, 40(4),
291-300.

Perš, J., Bon, M., Kovačič, S., Šibila, M., \& Dežman, B. (2002). Observation and analysis of large-scale human motion. Human Movement Science, 21, 295-311.

Preston-Dunlop, V. (1981). The nature of the Embodiment of Choreutic Units in Contemporary Choreography. London: Laban Center for Movement and Dance.

Prosen J., James, N., Dimitriou, L., Perš, J., \& Vučković, G. (2013). A Time-Motion Analysis of Turns Performed by Highly Ranked Viennese Waltz Dancers. Journal of Human Kinetics, 37(1), 55-62.

Štiavnický, M. (2004) Evaluation guidelines in dance sport. Bratislava: SZTŠ

Streškova, E., \& Chren, M. (2009). Balance ability level and sport performance in Latin-American dances. Physical Education and Sport, 7(1), 91-99.

Vermey, R. (1994). Latin. Thinking, sensing and doing in latin american dancing. Trento: Kastell Verlag.

Vučković, G., Perš, J., James, N., \& Hughes, M. (2009). Tactical use of the T area in squash by players of differing standard. Journal of Sport Science, 27(8), $863-871$

World Dance Sport Federation. (2019, September 15). WDSF Competition rules. Retrieved from World Dance Sport Federation website: https:// www.worlddancesport.org/Rule/Competition/General

Wyon, M. A., Abt, G., Redding, E., Head, A., Sharp, C. (2004). Oxygen Uptake During Modern Dance Class, Rehearsal, and Performance. Journal of Strength and Conditioning Research, 18(3), 646-649.

Zagorc, M., Karpljuk, D., \& Friedl, M. (1999). Analysis of functional strain in top sports dancers. D. Milanović, Ed., Collection of works "Kinesiology for 21st century", Zagreb: University of Zagreb, Faculty of Physical Culture, 240-244.

Zaletel, P., Vučković, G., James, N., Rebula, A., \& Zagorc, M. (2010b). A time-motion analysis of ballroom dancers using an automatic tracking system. Kinesiologica Slovenica, 16(3), 46-56.

Zaletel, P., Vučković, G., Rebula, A., \& Zagorc, M. (2010a). Analiza obremenitve plesnih parov pri izbranih standardnih in latinskoameriških plesih s pomočjo sledilnega sistema SAGIT [Analysis of dance couples` loading during selected ballroom and Latin-American dances using the SAGIT tracking system]. Šport, 58(3-4), 85-91. 